\title{
Ways of Analysis of Fire Effluents and Assessment of Toxic Hazards
}

\author{
Abdulrhman M. Dhabbah \\ Department of Forensic Science, King Fahad Security College, Riyadh, Saudi Arabia \\ Email: a_dhabbah@hotmail.com
}

Received 30 January 2015; accepted 17 February 2015; published 17 February 2015

Copyright (C) 2015 by author and Scientific Research Publishing Inc.

This work is licensed under the Creative Commons Attribution International License (CC BY). http://creativecommons.org/licenses/by/4.0/

\section{(c) (i) Open Access}

\begin{abstract}
Fire effluents, in most cases, have an adverse effect on human health and the environment. Exposure to some compounds may show both acute and chronic toxicity. There is a lack of knowledge on the effect of organic products on the human body in terms of the rate of organic material production in fires and their degree of toxicity. Thus, there is a need to expand the scope of studies about the organic products generated from fires and improve the methods of assessment to be included as part of fire hazard assessment. Different factors can be contributed to this lack of knowledge. For example, the composition of organic products generated from fires changes progressively and rapidly with progression of combustion and in a manner that is dependent on the fire condition. It is difficult to identify individual organic compounds produced during combustion. Another key factor is the lack of suitable instruments for measuring organic products generated from a fire. Also, the lack of procedures that are used to evaluate the lethal concentration limits and the lethal dose for a broad range of organic compounds generated from a fire may be another important factor which can be contributed to this lack of knowledge.
\end{abstract}

\section{Keywords}

Fire Effluents, Volatile Organic Compounds (VOCs), Semi-Volatile Organic Compounds (SVOCs), Polycyclic Aromatic Hydrocarbons (PAHs), Dioxins, Isocyanates

\section{Introduction}

Polymeric materials, whether natural or synthetic, play a crucial role in our life today. They are being used in daily production processes in different sectors such as construction, transport, electrical, electronic equipment, furniture, etc. Polymers have become indispensable materials, whose major disadvantage is their easy ignition and flame spread with many of toxic combustion products.

Initially, there are three types of test fires which have been used to classify fire hazards. The first is small- 
scale, which is used for determination of the ignitability and sometimes flame spread. The second are benchscale tests, which are used for the ignitability of fire spread as heat release of samples between $10 \mathrm{~g}$ and $250 \mathrm{~g}$ and for generating toxic fire effluents under controlled conditions. Finally, large scale tests are used for assessing the risks associated with specific scenarios regarding building, transport and then validating data from bench-scale tests and models of scale-up [1].

According to the International Organisation for Standardisation (ISO), fire is defined as the "process of combustion characterized by the emission of heat and fire effluents and is usually accompanied by smoke, flame, glowing or a combination thereof" [2]. Also, ISO has defined fire effluent as the "totality of gases and aerosols, including suspended particles, created by combustion or pyrolysis in a fire" [2]. Therefore, in fire atmospheres, fire effluents (toxic gases, visible smoke and heat) have a broad role negatively affecting safety of life [3]. A wide range of common materials produce a cocktail of combustion products, which have toxic effects ranging from asphyxiation and other acute toxic effects on sub-lethal or sub-acute effects [4] [5]. Fire statistics show that inhalation of fire effluents in fire is a major cause of both serious injuries and deaths from fire [6].

\section{Classification of Fire Effluent}

Fire effluents are formed in fire by either incomplete combustion or pyrolysis of materials. They can be classified into four main categories: asphyxiant (narcotic) gases, irritant gases, sub-acute toxicants and sub-lethal toxicants. The first category includes asphyxiant gases. In general, asphyxia can be defined as the deficient supply of oxygen to the human body, which prevents the oxygen uptake by cells, leading to unconsciousness and death [7]. The main asphyxiant gases include carbon monoxide ( $\mathrm{CO}$ ) and hydrogen cyanide (HCN). Carbon monoxide (CO) is a leading cause of death in fires resulting from the formation of carboxyhaemoglobin $(\mathrm{COHb})$ in the blood; this complex has a stability that is 200 times more than that of oxyhaemoglobin, which prevents the transport of oxygen from the lungs to the cells in the body [8]. Hydrogen cyanide (HCN) is also reported as one of the leading causes of death. It is released when the burning materials contain nitrogen such as wool, nylon, polyurethane and polyacrylonitrile [9]. It is also worth mentioning that toxicity of hydrogen cyanide is a factor of 20 greater than that of carbon monoxide [8].

The second category includes irritant gases. They are classified into organic and inorganic irritants depending on both the source and molecular structure of the compounds [7]. Significant organic irritants include oxygenated organics such as acrolein and formaldehyde. Inorganic irritants include nitrogen oxides, sulphur oxides and hydrogen halides [10] [11]. Hydrogen halides are released when the fire contains halogenated materials such as polyvinyl chloride, brominated flame retardants and polytetrafluoroethylene (teflon) [4].

Exposure to irritant gases and smoke may cause breathing difficulties with severe pain in eyes, nose, throat and chest, and in some cases lead to death either by impaired vision and preventing escape, or by inhalation of particulate matters which are sufficiently small to penetrate and accumulate in the respiratory tract [8] [12].

Two main effects occur upon exposure to irritants. First, painful sensory irritation occurs immediately in the upper respiratory tract, while lung inflammation and pulmonary oedema occur over a period of time deeper in the lung [12] [13].

The third category of fire toxicants includes sub-acute toxicants such as carcinogens; for instance volatile organic compounds (VOCs) such as benzene, and semi-volatile organic compounds (SVOCs) include polycyclic aromatic hydrocarbons (PAHs) such as naphthalene, benzo(a)pyrene and 2-nitrophenol.

The fourth category of fire toxicants corresponds to the sub-lethal toxicants which may exhibit a range of ill effects from respiratory sensitivity (such as isocyanates) toteratogenic and mutagenic effects, such as those caused by halogenated dibenzo-p-dioxins and dibenzofurans.

As mentioned earlier, as fire studies developed, most fire deaths have happened because of inhalation of toxic gases or impairing escape capability [8] [14]. Thus, one of the important roles of fire hazard assessment is the prediction of the hazards to life of people from exposure to fire effluents. Several combustion devices have been developed for understanding the role of combustion materials on the whole process of fire hazard assessment [15]. Therefore, quantifying the toxicity of a fire effluent is a fundamental component of any fire hazard analysis.

\section{Generation of Fire Effluents}

The degree of toxicity of combustion products depends on two factors; the material formulation and fire condi- 
tions [17]. The first factor has been discussed earlier. Regarding fire conditions, there are different stages that exhibit different types and yields of fire effluents: oxidative pre-ignition (non-flaming), early/well-ventilated flaming and fully developed under-ventilated flaming. Significant parameters used in distinguishing between the stages of fire conditions include heat fluxes, oxygen concentration, equivalence ratio, combustion efficiency and composition of materials [17] [18]. These stages have been classified in the ISO-19706 standard which is intended to serve as general guidelines for the assessment of the fire threat to people [19]. Table 1 shows the most important fire stages.

Some compounds have been identified in terms of assessment of their toxicity in the whole fire effluent. According to ISO carbon dioxide $\left(\mathrm{CO}_{2}\right)$, carbon monoxide $(\mathrm{CO})$, oxygen depletion $\left(\Delta \mathrm{O}_{2}\right)$, hydrogen chloride $(\mathrm{HCl})$, hydrogen bromide ( $\mathrm{HBr}$ ), hydrogen cyanide ( $\mathrm{HCN})$, hydrogen fluoride ( $\mathrm{HF})$, nitric oxide $(\mathrm{NO})$, nitrogen dioxide $\left(\mathrm{NO}_{2}\right)$ and sulphur dioxide $\left(\mathrm{SO}_{2}\right)$ as the main analytes for assessment of fire effluent toxicity. However, this list is not exhaustive; fires usually produce a mixture of organic compounds with varying degrees of toxicity [15].

The effects of these organic products on the human body in terms of toxicity are not fully understood. However, the materials and conditions which result in production of these toxicants are much poorly understood [8]. The reasons behind this can be attributed to several factors. First factor is the fact that the composition of organic products fire changes progressively and rapidly, depending on the fire conditions. Therefore, it is necessary to identify individual organic compounds produced during each stage of combustion. The second major factor is the lack of suitable instruments for quantifying yields of individual organic products generated in a fire. If 100 compounds are identified, the toxicity of each one needs to be multiplied by the amount detected in order to estimate which species make an important contribution to the toxicity. Although a plethora of medical committees all over the world have provided detailed tenability limits during work hours and industrial accidents. All these institutes try to cover a wide range of dangerous substances in the environment and fire. For example, a series of short term exposure limits (STELs) were provided by the Control of Substances Hazardous to Health in the UK [20], while a list of the immediately dangerous to life or health (IDLH) was established by the National Institute for Occupational Safety and Health (NIOSH) in the USA [21]. Similarly, the acute exposure guideline limits (AEGLs) were also provided by the National Academy of Science in the USA [22]. Nonetheless, there is still limited data showing lethal concentration limits and lethal doses for a wide range of organic compounds generated in a fire. Table 2 contains a summary of available limits for assessing some organic toxic compounds.

Generally, there is need to extend the scope of studies on fire toxicity to include organic products generated

Table 1. ISO classification of fire stages as on ISO-19706.

\begin{tabular}{|c|c|c|c|c|c|c|c|c|}
\hline \multirow[t]{2}{*}{ Fire stage } & \multirow[t]{2}{*}{$\begin{array}{c}\text { Heat } \\
\left(\mathrm{kW} \cdot \mathrm{m}^{-2}\right)\end{array}$} & \multicolumn{2}{|c|}{$\operatorname{Max}$ temp $\left({ }^{\circ} \mathrm{C}\right)$} & \multicolumn{2}{|c|}{ Oxygen $(\%)$} & \multirow{2}{*}{$\begin{array}{l}\text { Equivalence } \\
\quad \text { ratio } \phi\end{array}$} & \multirow[t]{2}{*}{$\mathrm{V}_{\mathrm{CO}} / \mathrm{V}_{\mathrm{CO} 2}$} & \multirow{2}{*}{$\begin{array}{l}\text { Combustion } \\
\text { efficiency }(\%)\end{array}$} \\
\hline & & Fuel & Smoke & In & Out & & & \\
\hline \multicolumn{9}{|c|}{ Non-flaming } \\
\hline $\begin{array}{l}\text { 1a. Self-sustained } \\
\text { smouldering }\end{array}$ & n.a. & $450-800$ & $25-85$ & 20 & $0-20$ & - & $0.1-1$ & $50-90$ \\
\hline $\begin{array}{l}\text { 1b. Oxidative, external } \\
\text { radiation }\end{array}$ & - & $300-600$ & & 20 & 20 & - & & \\
\hline $\begin{array}{l}\text { 1c. Anaerobic external } \\
\text { radiation }\end{array}$ & - & $100-500$ & & 0 & 0 & - & & \\
\hline \multicolumn{9}{|c|}{ Well-ventilated flaming } \\
\hline $\begin{array}{l}\text { 2. Well-ventilated } \\
\text { flaming }\end{array}$ & $0-60$ & $350-650$ & $50-500$ & 20 & $0-20$ & $<0.7$ & $<0.05$ & $>95$ \\
\hline \multicolumn{9}{|c|}{ Under-ventilated flaming } \\
\hline 3a. Low vent. room fire & $0-30$ & $300-600$ & $50-500$ & $15-20$ & $5-10$ & $>1.5$ & $0.2-0.4$ & $70-80$ \\
\hline 3b. Post-flashover & $50-150$ & $350-650$ & $>600$ & $<15$ & $<5$ & $>1.5$ & $0.1-0.4$ & $70-90$ \\
\hline
\end{tabular}


Table 2. Summary and comparison of potential toxicity assessment limits for some organic compounds.

\begin{tabular}{|c|c|c|c|c|c|c|c|c|c|c|c|c|}
\hline \multicolumn{3}{|c|}{ AEGL 30 m. (ppm) [22] } & \multicolumn{3}{|c|}{ AEGL $\underset{[22]}{10 ~ m . ~(p p m) ~}$} & \multirow{2}{*}{$\begin{array}{c}\text { IDLH } \\
(\mathbf{p p m})[21]\end{array}$} & \multirow{2}{*}{$\begin{array}{c}\mathbf{L C}_{\mathbf{5 0}} / \mathbf{R D}_{\mathbf{5 0}} \\
{[7]}\end{array}$} & \multirow{2}{*}{$\begin{array}{c}\mathbf{R D}_{\mathbf{5 0}} \\
(\mathbf{p p m})^{\prime} \\
{[7]}\end{array}$} & \multirow{2}{*}{$\begin{array}{c}\mathbf{L C}_{50} \\
(\mathbf{p p m})[7]\end{array}$} & \multirow{2}{*}{ Formula } & \multirow{2}{*}{$\begin{array}{c}\text { CAS } \\
\text { number }\end{array}$} & \multirow{2}{*}{ Toxic species } \\
\hline 3 & 2 & 1 & 3 & 2 & 1 & & & & & & & \\
\hline 5600 & 1100 & 73 & - & 2000 & 130 & 500 & 500 & 0.20 & 100 & $\mathrm{C}_{6} \mathrm{H}_{6}$ & $71-43-2$ & Benzene \\
\hline 6100 & 1600 & 200 & - & 3100 & 200 & 500 & & & & $\mathrm{C}_{7} \mathrm{H}_{8}$ & $108-88-7$ & Toluene \\
\hline 3600 & 1300 & 130 & - & 2500 & 130 & 900 & & & & $\mathrm{C}_{8} \mathrm{H}_{10}$ & $1330-20-7$ & Xylenes \\
\hline 14,000 & 4000 & 670 & - & 11,000 & 670 & - & & & & $\mathrm{CH}_{3} \mathrm{OH}$ & $76-56-1$ & Methanol \\
\hline 1100 & 340 & 45 & 1100 & 340 & 45 & 2000 & 15 & 4946 & $20,000-128,000$ & $\mathrm{C}_{2} \mathrm{H}_{4} \mathrm{O}$ & $70-07-0$ & Acetaldehyde \\
\hline 70 & 14 & 0.9 & 100 & 14 & 0.9 & 20 & 242 & 3.1 & $700-800$ & $\mathrm{CH}_{2} \mathrm{O}$ & $50-00-0$ & Formaldehyde \\
\hline 2.5 & 0.01 & 0 & 6.2 & 0.44 & 0 & 2 & 91 & 1.7 & $140-170$ & $\mathrm{C}_{3} \mathrm{H}_{5} \mathrm{O}$ & $107-02-8$ & Acrolein \\
\hline- & - & - & - & - & 5 & 30 & & & & $\mathrm{CH}_{2} \mathrm{O}_{2}$ & $64-18-6$ & Formic acid \\
\hline- & - & - & - & - & - & 50 & & & & $\mathrm{C}_{2} \mathrm{H}_{4} \mathrm{O}_{2}$ & $64-19-7$ & Acetic acid \\
\hline 27 & 8.9 & 0.19 & 44 & 27 & 0.19 & 50 & - & - & $200-1500$ & $\mathrm{C}_{4} \mathrm{H}_{6} \mathrm{O}$ & $123-73-9$ & Crotonaldehyde \\
\hline- & 29 & 19 & - & 29 & 19 & 250 & - & - & $400-700$ & $\mathrm{C}_{6} \mathrm{H}_{6} \mathrm{O}$ & $108-95-2$ & Phenol \\
\hline \multirow[t]{2}{*}{0.65} & 0.17 & 0.020 & 0.65 & 0.24 & 0.020 & 2.5 & & & & $\mathrm{C}_{9} \mathrm{H}_{6} \mathrm{~N}_{2} \mathrm{O}_{2}$ & $584-84-9$ & $\begin{array}{c}\text { Toluene } \\
\text { diisocyanate (TDI) }\end{array}$ \\
\hline & & & & & & 75 & & & & $\mathrm{C}_{15} \mathrm{H}_{10} \mathrm{~N}_{2} \mathrm{O}_{2}$ & 101-68-8 & $\begin{array}{c}\text { Methylene } \\
\text { bisphenylisocyanate } \\
\text { (MDI) }\end{array}$ \\
\hline 0.036 & 0.012 & - & 0.036 & 0.012 & - & & & & & $\mathrm{C}_{7} \mathrm{H}_{5} \mathrm{NO}$ & $103-71-9$ & $\begin{array}{c}\text { Phenyl } \\
\text { isocyanate }\end{array}$ \\
\hline 0.40 & 0.13 & - & 1.2 & 0.40 & - & 3 & & & & $\mathrm{C}_{2} \mathrm{H}_{3} \mathrm{NO}$ & $624-83-9$ & $\begin{array}{l}\text { Methyl } \\
\text { isocyanate }\end{array}$ \\
\hline 950 & 400 & 17 & 950 & 580 & 17 & 500 & & & & $\mathrm{C}_{4} \mathrm{H}_{8} \mathrm{O}_{2}$ & $123-91-1$ & 1,4-Dioxane \\
\hline 27 & 8.9 & 0.19 & 44 & 27 & 0.19 & 50 & & & & $\mathrm{C}_{4} \mathrm{H}_{6} \mathrm{O}$ & $123-73-9$ & $\begin{array}{c}\text { Trans- } \\
\text { crotonaldehyde }\end{array}$ \\
\hline
\end{tabular}

from fires and improve methods of assessment to be a part of fire hazard assessment.

\section{Characterization of Organic Compounds}

Organic compounds are considered as the most important products in fire effluents. They include a very large and varied number of compounds. Thus, their sampling and analysis are considered to be one of the biggest problems in fire as a result of difficulty in identifying the species and knowing their impact on the human body. However, it is possible to mention some information about characterization of organic compounds as follows.

\subsection{Organo Irritants}

Organo irritants are formed and released in fire atmospheres through the pyrolysis under oxygen deficient conditions for materials. The production of this type of compounds is associated with large numbers of known organic materials. Depending on the type of materials, it can be estimated that organic products in fire are either innocuous or noxious. In general, the main pyrolysis products for simple hydrocarbon polymers such as polyethylene or polypropylene are innocuous. For example, no effect upon primates was found when polypropylene is pyrolysed in nitrogen. In this case, the main products are ethylene, ethane, propene, cyclopropan, formaldehyde, butane, acetaldehyde, toluene and styrene. In contrast, when these products are oxidized in air throughout the smouldering decomposition, some of them are converted to extremely irritant products. Practically, these products showed clear effects on both mice and primates which were found in an atmosphere of fire. 
<smiles>CC=O</smiles>

acetaldehyde<smiles>Cc1ccccc1</smiles>

toluene<smiles>C=Cc1ccccc1</smiles>

styrene

It is worth mentioning that several studies were carried out on some materials with and without fire retardant additives. The results of these experiments have confirmed that the pyrolysis of a polymer with fire retardant substances gives off the products 300 times more irritant than the pyrolysis of the same polymer without fire retardants [23].

\subsection{Polycyclic Aromatic Hydrocarbons (PAHs)}

Polycyclic aromatic hydrocarbons (PAHs) are considered one of the largest groups of organic compounds; that consist of two or more joined aromatic rings. They are formed essentially as a result of incomplete combustion of organic materials through combustion atmospheres. PAHs can be formed through small unstable precursor compounds by two paths. In the first path, they are formed immediately from saturated hydrocarbons in an environment without enough oxygen. In this case, low molecular weight hydrocarbons operate as precursors in the pyro-synthesis of PAHs compounds that happen at temperatures above $500^{\circ} \mathrm{C}$. The second path corresponds to thermal breakdown of heavier hydrocarbons. From these processes, several hundreds of PAHs have been investigated in most detail in the conditions of an incomplete combustion. The best known is benzo [a] pyrene (BaP), whose metabolites are mutagenic and highly carcinogenic in the body. Further, a quantity of heterocyclic aromatic compounds such as carbazole, acridine as well as nitro-PAHs can be generated.

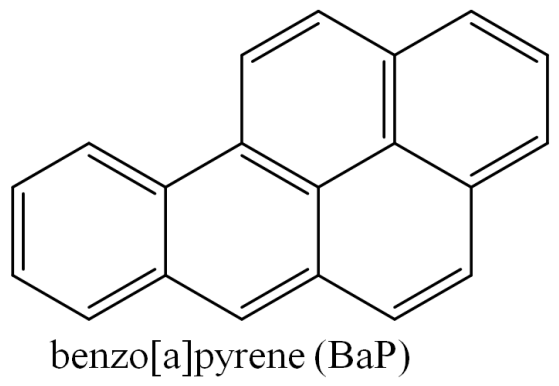

It was proven that individual PAHs are toxic; also, they can cause a variety of non-cancer (mutagenicity, teratogenicity) and cancer effects [24]. Inhalation of PAHs is one of the main causes of cancer. For this reason, the U.S. Environmental Protection Agency (EPA) has established the toxicity equivalency factor (TEF) as a reference scale for evaluation of the risks and the toxicity of a chemical or a mixture of chemical compounds. Regarding PAHs, $\mathrm{BaP}$ normally is used as the reference compound which corresponds to 1.0 as TEF [24] [25].

\subsection{Isocyanates}

Isocyanates are a group of organic compounds characterized by their extremely reactive group $(\mathrm{N}=\mathrm{C}=\mathrm{O})$ toward a variety of nucleophilic compounds such as alcohols, amines and water. They can be classified into three types based on the number of $\mathrm{N}=\mathrm{C}=\mathrm{O}$ groups in the molecule: monoisocyanates (one $\mathrm{NCO}$ ) such as methylisocyanate (MIC), diisocyanates (two NCO groups) such as 2,4-toluene diisocyanate (2,4-TDI), and polyisocyanates (multiple NCOs) such as polymeric methylene diphenylisocyanate (polymeric MDI). Further, it is possible to classify isocyanates as either saturated (aliphatic and alicyclic) or aromatic (one or more aromatic rings) [26]-[28]. It is worth mentioning that diisocyanates are considered as the most important group of isocyanates, because they contain two NCO groups which allow direct polymerization reactions to occur with alcohols and formation of polyurethanes (PUR) which are used in many industrial and technical fields [26]. 


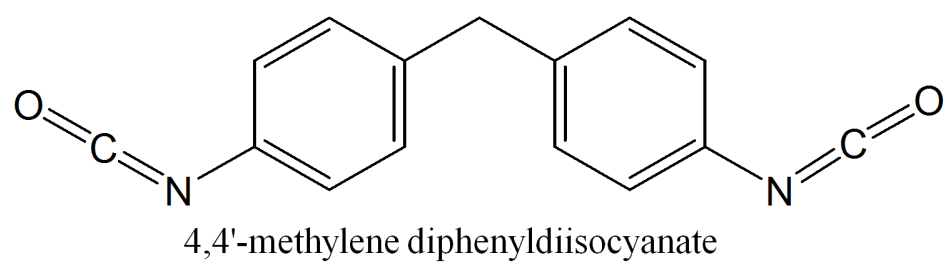

Isocyanates are widely used in many syntheses, particularly for manufacturing of polymers. They are formed in any state of matter - as gases, droplets or particles. Thus, when these compounds are inhaled, various adverse health effects may happen as a result of binding them with human tissues, proteins and DNA, with production of toxic adducts and metabolites [27] [28]. There are a lot of diseases which may be caused by isocyanates including asthma, which is considered as the most common clinical diagnosis, chronic obstructive pulmonary disease (COPD), non-obstructive, extrinsic allergic alveolitis and cancer [27] [28].

\subsection{Dioxins}

When incomplete combustion happens, a wide range of organic compounds are produced including dioxins which are Polychlorinated dibenzo-p-dioxins (PCDDs) and Polychlorinated dibenzofurans (PCDFs). Both these types of compounds share a common basic molecular structure which comprised two aromatic rings. Two ether-bridges join the two rings in the case of PCDFs, whereas in the case of PCDDs, they are linked by one etherbridge and one carbon-carbon bond in a heterocyclic arrangement. Further, these compounds can be substituted by up to eight chlorine atoms; thus, there are 75 individuals of PCDDs and 135 individual of PCDFs. In contrast, the molecular structure of 2,3,7,8-tetrachlorodibenzo-p-dioxin (2,3,7,8-TCDD) is considered as the highest toxic compound in dioxins with many effects including immunotoxicity, acute dermal toxicity, reproductive health effects, teratogenicity disruption and carcinogenicity [27]-[29].<smiles>Clc1ccc2c(c1)Oc1ccccc1O2</smiles>

Polychlorinated dibenzo-p-dioxins (PCDDs)

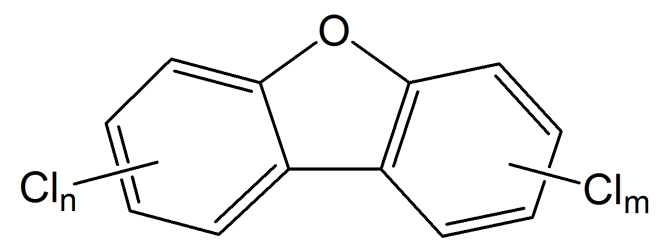

Polychlorinated dibenzofurans (PCDFs)

In general, there are 17 congeners of dioxin species (7 for PCDDs and 10 for PCDFs) with chlorine atoms substituted at positions 2, 3, 7 and 8 . Their characteristics resemble those of 2,3,7,8-TCDD. Inhalation of dioxins is considered one of the main causes of cancer. For this reason, 2,3,7,8-TCDD is used as the reference compound for toxicity which corresponds to a value of 1.0 as TEF [27].

\subsection{Organophosphates}

Organophosphates (OPs) compounds have been widely used for industrial applications such as seat cushions, pesticides and fire retardants as phosphorus fire retardants (PFRs) [30] [31]. In contrast, when exposed to OPs products, a wide range of neurotoxic effects occur by targeting the nervous system or the enzymatic system in living organisms. Several symptoms can result from exposition to OPs such as convulsions, respiratory failure, and cardiac arrhythmias [31]. 


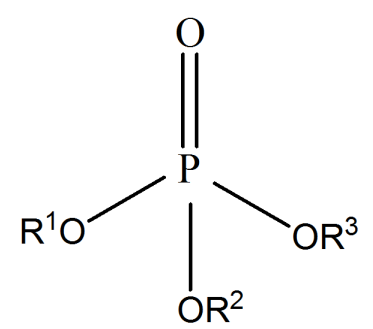

General structure of an organophosphate

\subsection{Aerosols/Particulates}

Fire-generated aerosols or particulates may cause death either by smoking which impairs escape ability by obscuring an exit route, or by producing chronic health effects and environmental hazards from chemical compounds contained in the aerosol. Particulate matters are dangerous as a result of their ability to penetrate into pulmonary tract and to pose a respiratory hazard [23] [32]. The terms and definitions of aerosol, particles and droplets were proposed as given in ISO 13943 as follows.

The first term is aerosol which is defined as a suspension of liquid droplets, or solid particles in a gas phase matrix. Furthermore, the particle sizes range from under $10 \mathrm{~nm}$ to over $10 \mu \mathrm{m}$. The second type is particles which are defined as solid-phase products present in aerosols. There are two categories of fire aerosol particles: either particles produced from incomplete combusted matter (i.e. "soot") containing a high proportion of carbon with spherical shape and about $1 \mu \mathrm{m}$ in diameter, or particles produced from complete combusted materials consisting of small particle sized "ashes". In general, formation of soot particles is dependent on many parameters, including the types of materials, temperature, and fire conditions. The third type is droplets which are defined as liquid-phase products present in aerosols. This kind is typically generated through pyrolysis when there is not enough oxygen from both flaming and smouldering fires. Further, the condensation of water produces from combustion, around particles is possible and therefore forming aerosol droplets [32]. It is noteworthy to mention that the term particulate matter (PM) is a generic term related to an aerosol as a chemically heterogeneous material including both particles and liquid droplets found in the air.

Aerosol or particulates are generally categorised based on size:

- ultrafine particles are less than $0.1 \mu \mathrm{m}$ in diameter;

- fine particles are between 0.1 and $2.5 \mu \mathrm{m}$ in diameter;

- coarse particles are between 2.5 and $10 \mu \mathrm{m}$ in diameter;

- super-coarse particles are larger than $10 \mu \mathrm{m}$ in diameter [33].

On the other hand, it is possible to inhale aerosols to various depths into the lungs, depending on their size and density; they can also be released into the environment and accumulate on land and in waterways.

The main biological effect of aerosols is preventing gas exchange which causes oedema and inflammation of the terminal bronchioles. Further, it is important to know that the smallest particles $(<0.5 \mu \mathrm{m})$ can penetrate into the lungs causing interstitial and luminal oedema which is very dangerous [23].

\section{Sampling of Fire Effluents}

Sampling is a great challenge for analysts in the fire field. It is considered the most critical part of the procedures for analysis of species and particulates in fire effluent. There are two reasons for this state of affairs. The first is that the components generated in fire atmospheres can contain a wide range of compounds and phases as well as the concentration of species in the smoke plume may change either from ppm-levels to percentage-levels or from one part of the plume to another during the course of the fire. In addition, different species have various properties. Some of them are corrosive while others are unstable or condensable vapours (including water) and aerosols which are not readily or clearly separated. The second reason is assigned to temperatures in fire atmospheres that may typically exceed $1000^{\circ} \mathrm{C}$. Therefore, in most cases, gas products are hot at the sampling point which causes complications such as continued chemical reactions, or condensation of gases in different parts of the sampling device. Hence, different chemical processes may have occurred generating a mixture of novel organic molecules [15] [27] [34].

In order to understand the effects of mixtures of toxic gases which are produced in fire effluents, it is neces- 
sary to use different methods to assess fire toxicity by having knowledge of the range, nature and concentration of species present in fire atmospheres. Several analytical methods are required to reach this goal. Therefore, a number of experimental procedures are necessary for the proper investigation of combustion products yields [6].

Ideally, the requirement for any fire effluent sampling system is to obtain a representative and realistic sample in the atmosphere tested bearing in mind that the sample should not be affected by the sampling system. Practically, this goal is achieved when a number of factors including the nature of the species, the temperature, and type of material used for the sampling probe and extract tubing, the flow rate of the sample, the type and position of both particulate filters, and condensate traps. Therefore, it is necessary to take these factors into account when sampling and analysing a fire effluent to ensure accurate identification and quantification of fire effluent products [15] [34].

To enable the fire condition to be reliably known, for the species of interest to be generated in a fire, the steady state tube furnace SSTF (ISO DIS 19700) has proved to be reliable. It can be used to model a wide variety of fire conditions such as non-flaming, early/well-ventilated flaming and fully developed under-ventilated flaming via different combinations of temperature and different fuel/oxygen ratios. The SSTF device (ISO DIS 19700) can replicate a broad range of well-controlled combustion conditions.

Some criteria for sampling effluents are to be taken into account. For example, it is necessary to extract samples from the test atmosphere using inert sampling lines and pumps. Also, it is essential to use some suitable traps and filters, such as packed particulate traps for removing moisture before conducting the analysis, but after any heated sections of sampling tubes, to ensure that the fire effluents are free from interference before introducing them into the analysis apparatus. For this process, it is appropriate to use some agents such as glass wool to remove particulates, and calcium sulphate or calcium chloride to remove water [34].

\subsection{Sampling of Organic Compounds in Fire}

Generally, a wide range of cumulative methods are available to sample and analyze organic species. These methods are various and depend on which nature of organic species is to be quantified [27] [35]. The ISO 19701: 2013 standard describes in detail all these methods [34].

\subsubsection{Volatile Organic Compounds (VOCs)}

It is possible to measure and sample VOCs from fire gases by using commercial adsorbent tubes called Tenax. The species which can be extracted by this method include a range of non-polar or slightly polar small-medium sized hydrocarbon species with a molecular weight of approximately $75-200 \mathrm{amu}$. Thereafter, the sample can be analyzed by thermal desorption and then introduced to a high resolution gas chromatograph with mass spectrometric detection (GC-MS). On the other hand, commercially available activated carbon tubes can be used in the case of sampling and capturing smaller gaseous species. Relatively small sampling flows can be used for these types of commercial adsorbent tubes.

For large-scale fire gas analysis, an alternative sampling method has been developed. This method set-up consists of:

1) one tube containing Amberlite XAD-2 resin to collect higher molecular weight species;

2) a cooled (approximately at $-10^{\circ} \mathrm{C}$ ) U-tube to trap and condense water;

3) one activated carbon adsorption tube cooled to $-50^{\circ} \mathrm{C}$ to collect lower molecular weight species.

In this method, greater amounts of organic compounds can be adsorbed. Furthermore, because of a relatively high sampling flow, there is no worry about risking losses in the sampling.

Both of these methods have advantages and disadvantages, as detailed below. The main advantage of the large-scale method is the possibility to perform multiple analyses on the same extracted sample. The main disadvantages of the large-scale method are:

1) the possibility of some interferences occurring between the extracted species and the solvent;

2) the possibility of diluting the samples below the minimum detection limit by the solvent.

In contrast, in the case of thermal desorption, the main advantage is avoiding these effects (1 and 2), no dilution and interference can occur from a solvent, while the main disadvantage of this method is that the whole sample is consumed in a single analysis [34] [35].

\subsubsection{Aldehydes}

Aldehydes can be sampled on cartridges consisting of silica gel covered with 2,4-dinitrophenylhydrazine (DNPH). 
It is worth mentioning that aldehydes have to be stabilised before analysis because of their high irritancy and their reactivity. The cartridges can be extracted with acetonitrile. Meanwhile it is possible to collect hydrazones separated by reversed-phase high performance liquid chromatography (HPLC). Samples can then be analyzed using an UV/VIS detector for formaldehyde and acetaldehyde or by atmospheric pressure chemical ionization-mass spectrometry (APCI-MS) which is preferable for all other aldehydes and ketones [34] [35].

\subsubsection{Semi-Volatile/Condensed Phase Organics}

Large organic compounds with high boiling points, such as polycyclic aromatic hydrocarbons (PAHs) and chlorinated or brominated dibenzo-dioxins and furans (PCDDs/PCDFs and PBDDs/PBDFs), tend to be adsorbed on particles in smoke gases. Thus, it is important to use a method that enables to collect a representative sample depending on particle size distribution. For this reason, a large sampling volume is the best choice for collection semi-volatile compounds. To get a sampling speed in the orifice of the tip that is equal to that of the gas speed in the smoke gas collector duct, the diameter of the sample-probe tip should be adjusted with the sampling flow.

The sampling system should consist of:

1) a heated glass fiber filter;

2) a water-cooled condenser with a condensate bottle;

3) a large adsorbent cartridge containing XAD-2 amberlite.

This type of sampling system is commonly used in Scandinavia.

There is another method for sampling of PAHs and PCDDs/PCDFs found in EN 1948 standard, which is in close agreement with the previous method. The difference between the two methods is that it is possible to use an adsorbent cartridge instead of using the impinger bottles which are described in the standard methods [35] $[36]$.

\subsubsection{Isocyanates}

Isocyanate compounds (including isocyanates, aminoisocyanates and amines) are very reactive species. These compounds can be sampled via an impinger-filter sampling system. In order to sample airborne isocyanates, it is necessary to use an impinger flask, which contains a reagent solution of di-n-butylamine(DBA) in toluene to form specific DBA-isocyanate derivatives. Furthermore, it is essential to place a glass fiber filter after the impinger. Subsequently, if the size of particles is large $(>1.5 \mu \mathrm{m})$, they will retain in the impinger solution, whereas if the size of the particles is smaller $(0.01-1.5 \mu \mathrm{m})$, they will pass all the way through the impinger solution and can be collected by the filter. It is important to bear in mind when conducting analyses of the species separately with both of the impinger solution and the filters. After that, the species can be analysed by the hyphenated technique liquid chromatography separation with mass spectroscopic detection (LC-MS) which shows a highly sensitive measurement of isocyanates, at detection limit equivalent to 0.0005 of the Swedish threshold limit value(TLV) [5] [27] [34].

\subsubsection{Organophosphates}

For sampling organophosphates, it is necessary to pump the fire atmosphere at $0.4 \mathrm{~L} / \mathrm{min}$ for $4 \mathrm{~min}$ to $5 \mathrm{~min}$ through a fritted bubbler containing $20 \mathrm{~mL}$ of $0.01 \mathrm{M}$ sodium hydroxide, and record the total volume sampled. In order that both particulate and vapour form organophosphates can be measured, a glass fibre filter can set before the bubbler, which is then desorbed in $20 \mathrm{~mL} 0.01 \mathrm{M} \mathrm{NaOH}$ or other appropriate aqueous medium prior to analysis. However, these sampling parameters may vary from case to case if necessary to suit conditions [34].

\subsubsection{Aerosols/Particulates}

Special techniques are required for sampling of particulates in fire effluents, which are different in some respects compared with sampling methods which are used for gases. There are four main properties which could be characteristic for both solid and liquid particulates in fire effluents:

- concentration;

- particle size distribution;

- chemical nature (which might rely on particle size);

- morphology (i.e. form and structure ), which might rely on the chemical nature of particulates.

During the sampling of aerosols and particulates, it is necessary to attempt to preserve all these properties. On the other hand, the sampling probe used should be designed to operate at a velocity set to supply isokinetic sam- 
pling. This means that the velocity of sampling is similar to the velocity of the sampled effluent flow. The benefit of this process is to avoid any change in concentration or particle characteristics through the use of the probe. In addition, it is important to adjust the temperature of the probe, sampling lines, pressure and the material to get acceptable results [15].

\section{Analysis of Fire Effluents}

After generation of combustion products, two choices are available for sampling and analysis; either in situ for immediate analysis or extractive for subsequent analysis. In situ sampling is the method in which the chemical species are measured directly at their point of generation. Extractive sampling is the method in which the samples are collected from the fire test or experiment for analysis either immediately or at a later step. Generally, the extractive methods are more common than in situ methods [15].

In situ analysis includes the use of non-dispersive infrared (NDIR), paramagnetism analysis and Fourier transform infrared spectroscopy (FTIR) as a direct continuous and semi-continuous analysis for determination of carbon dioxide $\left(\mathrm{CO}_{2}\right)$, carbon monoxide $(\mathrm{CO})$, oxygen and a variety of volatile inorganic and organic species.

Extraction of samples may be done by the methods including:

- using a sampling line as indirect analysis then followed by gas chromatography (GC) or gas chromatography coupled to mass spectrometry (GC-MS) for analysis of many of inorganic and organic species;

- using a trapping solid adsorbent such as activated charcoal followed by gas chromatography and mass spectrometry (GC-MS) or gas chromatography equipped with flame ionization detector (GC-FID) for analysis of benzene, volatile organic compounds (VOCs) and polycyclic aromatic hydrocarbons (PAHs);

- using a trapping solution in liquid phase such as sodium hydroxide $(\mathrm{NaOH})$ and hydrogen peroxide $\left(\mathrm{H}_{2} \mathrm{O}_{2}\right)$ in gas-washing bottles, bubblers or impingers followed by gas chromatography and mass spectrometry (GC-MS) for analysis of the volatile organic compounds (VOCs) and polycyclic aromatic hydrocarbons (PAHs);

- using gas bags for analysis of nitrogen oxides and some of the volatile organic compounds (VOCs) [15].

\section{Conclusions}

It is important to note that a lot of species have proven to play an essential role after considering their contribution to the toxicity of the whole fire effluent. The majority of the toxic organic compounds are formed and released in fires. In particular, they result from incomplete combustion. Emission of these products from fires, in most cases, has an adverse effect on human health and the environment. Exposure to some compounds such as volatile organic compounds (VOCs), semi-volatile organic compounds (SOVCs), polycyclic aromatic hydrocarbons (PAHs), dioxins and isocyanates may show both acute and chronic toxicity. However, this list is not exhaustive, because burning any material usually produces a complex mixture of organic compounds, with varying degrees of toxicity [15].

The emission of organic compounds from fires, in most cases, has negative effects on the contamination of the environment and health of human. Therefore, these toxic products are most likely to cause some diseases, which include sub-acute effects and sub-lethal effects. Moreover, there is a concern regarding their potential carcinogenicity, ill effects from respiratory sensitizes, to teratogenic and mutagenic effects, particularly for persons that are frequently exposed to these organic compounds. Furthermore, it is important to note that exposure to organic compounds during a fire can lead to fatal lung damage over periods of some hours to many days later than exposure, or permanent lung damage in survivors. The main fatal effects are lung inflammation and oedema, bronchiolitis obliterans, and bronchopneumonia [13].

In fact, there is a lack of knowledge on the effect of organic products on the human body in terms of the rate of organic material production in fires and their degree of toxicity [8]. The reasons behind this can be attributed to several factors. The first one is the fact that the composition of organic products generated from fire changes progressively and rapidly with the progress of combustion and in a manner that is dependent on the fire condition. Therefore, it is difficult to identify individual organic compounds produced during combustion. The second major factor is the lack of suitable instruments for measuring organic products generated from a fire. A third factor is the lack of procedures that are used to evaluate the lethal concentration limits and a lethal dose for a broad range of organic compounds generated from a fire.

Thus, there is a need to expand the scope of studies about the organic products generated from fires and improve the methods of assessment to be included as part of fire hazard assessment. 


\section{Acknowledgements}

The Author extends his appreciation to King Fahad Security College (Riyadh, Kingdom of Saudi Arabia) for supporting this work. He is also grateful to Professor T. Richard Hull and Dr. Anna Stec from University of Central Lancashire, School of Forensic and Investigative Sciences (Preston, United Kingdom) and Professor A. Yacine Badjah Hadj Ahmed from King Saud University, College of Science (Riyadh, Kingdom of Saudi Arabia) for their kind assistance.

\section{References}

[1] Hull, T.R. (2010) 12-Bench-Scale Generation of Fire Effluents. In: Stec, A. and Hull, T.R., Eds., Fire Toxicity, Woodhead Publishing Ltd., Cambridge, 424-460. http://dx.doi.org/10.1533/9781845698072.4.424

[2] ISO (International Standards Orgnisation) (2008) ISO 13943.

[3] Gann, R. (2008) Fire Effluent, People, and Standards: Standardization Philosophy for the Effects of Fire Effluent on Human Tenability. Interscience, London.

[4] Alarie, Y. (2002) Toxicity of Fire Smoke. Critical Reviews in Toxicology, 32, 259-289. http://dx.doi.org/10.1080/20024091064246

[5] Gann, R., Averill, J.D., Butler, K.M., Jones, W., Mulholland, G.W., Neviaser, J.L., et al. ( 2001) International Study of the Sublethal Effects of Fire Smoke on Survivability and Health (SEFS) : Phase I Final Report. National Institute of Standards and Technology, Gaithersburg, Md. http://dx.doi.org/10.6028/NIST.TN.1439

[6] Stec, A.A., Hull, T.R., Purser, J.A. and Purser, D.A. (2009) Comparison of Toxic Product Yields from Bench-Scale to ISO Room. Fire Safety Journal, 44, 62-70. http://dx.doi.org/10.1016/j.firesaf.2008.03.005

[7] Purser, D.A. (2006) Assessment of Hazards to Occupants from Smoke, Toxic Gases, and Heat. In: Di Nenno, P.J., Ed., The SFPE Handbook of Fire Protection Engineering, 4th Edition, National Fire Protection Association, Quincy, 96193.

[8] Hull, T.R. and Stec, A. (2010) Introduction to Fire Toxicity. In: Hull, T.R. and Stec, A., Eds., Fire Toxicity, Woodhead Publishing Ltd., Cambridge, 1-25. http://dx.doi.org/10.1533/9781845698072.1.3

[9] Lestari, F. (2006) Development of in Vitro Toxicity Methods for Fire Combustion Products. Ph.D. Thesis, The University of New South Wales, Sydney, 7-71.

[10] Lemieux, P.M., Lutes, C.C. and Santoianni, D.A. (2004) Emissions of Organic Air Toxics from Open Burning: A Comprehensive Review. Progress in Energy and Combustion Science, 30, 1-32. http://dx.doi.org/10.1016/j.pecs.2003.08.001

[11] Purser, D. (2012) Validation of Additive Models for Lethal Toxicity of Fire Effluent Mixtures. Polymer Degradation and Stability, 97, 2552-2561. http://dx.doi.org/10.1016/j.polymdegradstab.2012.07.009

[12] Purser, D. (1992) The Evolution of Toxic Effluents in Fires and the Assessment of Toxic Hazard. Toxicology Letters, 64-65, 247-255. http://dx.doi.org/10.1016/0378-4274(92)90196-Q

[13] Purser, D.A. (2010) 3-Hazaeds from Smoke and Irritants. In: Stec, A. and Hull, T.R., Eds., Fire Toxicity, Woodhead Publishing Ltd., Cambridge, 51-117. http://dx.doi.org/10.1533/9781845698072.2.51

[14] Hull, T., Stec, A. and Paul, K. (2008) Hydrogen Chloride in Fires. Fire Safety Science, 9, 665-676. http://dx.doi.org/10.3801/IAFSS.FSS.9-665

[15] Fardell, P. and Guillaume, E. (2010) 11-Sampling and Measurement of Toxic Fire Effluent. In: Stec, A. and Hull, T.R., Eds., Fire Toxicity, Woodhead Publishing Ltd., Cambridge, 385-423. http://dx.doi.org/10.1533/9781845698072.4.385

[16] Hull, T.R., Lebek, K., Pezzani, M. and Messa, S. (2008) Comparison of Toxic Product Yields of Burning Cables in Bench and Large-Scale Experiments. Fire Safety Journal, 43, 140-150. http://dx.doi.org/10.1016/j.firesaf.2007.06.004

[17] Purser, D., Stec, A. and Hull, R. (2010) 2-Fire Scenarios and Combustion Conditions. In: Stec, A. and Hull, T.R., Eds., Fire Toxicity, Woodhead Publishing Ltd., Cambridge, 26-47. http://dx.doi.org/10.1533/9781845698072.1.26

[18] Hull, T.R.A., Stec, A., Lebek, K. and Price, D. (2007) Factors Affecting the Combustion Toxicity of Polymeric Materials. Polymer Degradation and Stability, 92, 2239-2246. http://dx.doi.org/10.1016/j.polymdegradstab.2007.03.032

[19] ISO/TS 19706 (2004) Guidelines for Assessing the Fire Threat to People.

[20] EH40/2005 Workplace Exposure Limits (2011) List of Approved Workplace Exposure Limits. Health and Safety Executive, 9-26.

[21] D. for I.D.T.L. or H.C. (IDLHs) (1994) Chemical Listing and Documentation of Revised IDLH Values (as of 3/1/95). 
NIOSH Publications and Products.

[22] National Research Council of the National Academies (2014) Acute Exposure Guideline Levels, Acute Exposure Guideline Levels for Selected Airborne Chemicals. The National Academies Press, Washington DC, Vol. 17, 3-9.

[23] Stec, A.A. and Hull, T.R. (2009) Chapter 17: Fire Toxicity and Its Assessment.

[24] Blomqvist, P., McNamee, M.S., Andersson, P. and Lönnermark, A. (2012) Polycyclic Aromatic Hydrocarbons (PAHs) Quantified in Large-Scale Fire Experiments. Fire Technology, 48, 513-528. http://dx.doi.org/10.1007/s10694-011-0242-9

[25] Lodgejr, J. (1996) 5-Organic Pollutants, Air Quality Guidelines for Europe. Environmental Science and Pollution Research, 3, 59-120. http://dx.doi.org/10.1007/BF02986808

[26] Bello, D., Woskie, Ã.S.R., Streicher, R.P., Liu, Y., Stowe, M.H., Eisen, E.A., et al. (2004) Polyisocyanates in Occupational Environments : A Critical Review of Exposure Limits and Metrics. American Journal of Industrial Medicine, 46, 480-491.

[27] Blomqvist, P. (2005) Emissions from Fires, Consequences for Human Safety and the Environment. Ph.D. Thesis, Department of Fire Safety Engineering, Lund Institute of Technology, Lund University, Lund.

[28] Hoesbjoer, H.N., Norwegian, T. and Inspection, L. (2001) International Consensus Report on: Isocyanates-Risk Assessment and Management. Nordic Council of Ministers, 1-131.

[29] Stanmore, B. (2004) The Formation of Dioxins in Combustion Systems. Combustion and Flame, 136, 398-427. http://dx.doi.org/10.1016/j.combustflame.2003.11.004

[30] Van der Veen, I. and de Boer, J. (2012) Phosphorus Flame Retardants: Properties, Production, Environmental Occurrence, Toxicity and Analysis. Chemosphere, 88, 1119-1153. http://dx.doi.org/10.1016/j.chemosphere.2012.03.067

[31] Russo, M.V., Avino, P., Cinelli, G. and Notardonato, I. (2012) Sampling of Organophosphorus Pesticides at Trace Levels in the Atmosphere Using XAD-2 Adsorbent and Analysis by Gas Chromatography Coupled with Nitrogen-Phosphorus and Ion-Trap Mass Spectrometry Detectors. Analytical and Bioanalytical Chemistry, 404, 1517-1527. http://dx.doi.org/10.1007/s00216-012-6205-2

[32] ISO/DIS 29904 (2013) Fire Chemistry - Generation and Measurement of Aerosols, ISO the International Organization for Standardization, Geneva.

[33] Castranova, V. (2011) Factors Governing Pulmonary Response to Inhaled Particulate Matter. 3rd Edition, John Wiley \& Sons, Inc., Hoboken, 793-803. http://dx.doi.org/10.1002/9781118001684.ch38

[34] BS ISO 19701 (2005) Methods for Sampling and Analysis of Fire Effluents. British Standards Institution.

[35] Blomqvist, P. Simonson-McNamee, M. (2010) 13-Large-Scale Generation and Characterisation of Fire Effluents. In: Stec, A. and Hull, T.R., Eds., Fire Toxicity, Woodhead Publishing Ltd., Cambridge, 461-514. http://dx.doi.org/10.1533/9781845698072.4.461

[36] EN1948-1 (1997) Stationary Source Emissions-Determination of the Mass Concentration of PCDDs/PCDFs-Part 1: Sampling. 
Scientific Research Publishing (SCIRP) is one of the largest Open Access journal publishers. It is currently publishing more than 200 open access, online, peer-reviewed journals covering a wide range of academic disciplines. SCIRP serves the worldwide academic communities and contributes to the progress and application of science with its publication.

Other selected journals from SCIRP are listed as below. Submit your manuscript to us via either submit@scirp.org or Online Submission Portal.
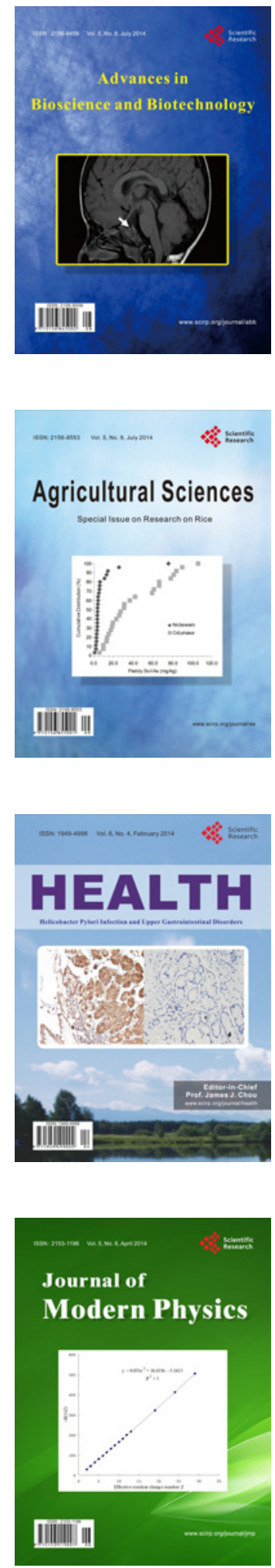
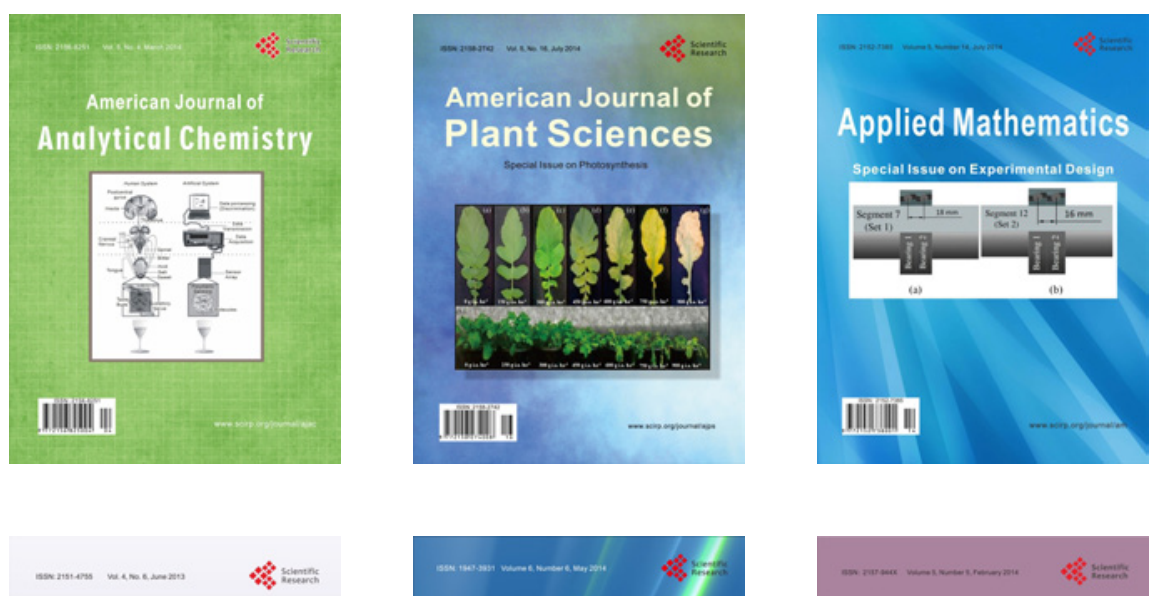

Creative Education
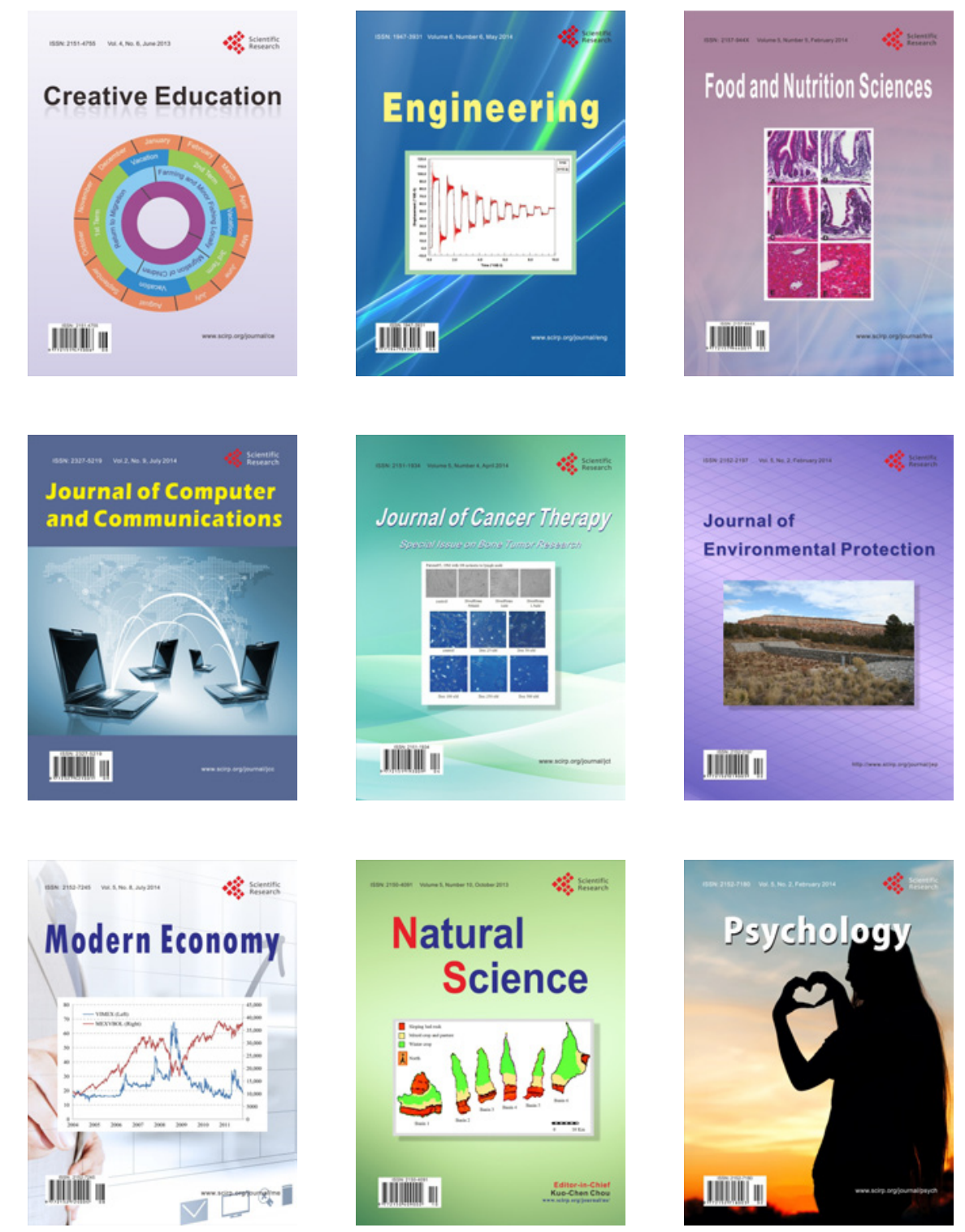